\title{
News from the Underground
}

\section{ERS Annual Congress}

Another excellent meeting has come to an end! This year, the $23^{\text {rd }}$ ERS Annual Congress had close to 21000 delegates presenting and discussing the latest advances in respiratory research. And there was a buzz surrounding junior members. Not only was the importance of junior members mentioned in the President's speech at the Opening Ceremony but also the presence and contributions from juniors were sought at Assembly meetings. And, of course, juniors were there and the Junior Member Committee was there too!

The ERS Annual Congress had a variety of special events for juniors. The Fellows' Get Together is the session to attend for great advice on building up your career and on increasing your chances of becoming an ERS Fellow. The Fellows' Get Together on Saturday was a fantastic session. It allowed for previous and future fellows to share their work and experiences, with ample time for discussion with the audience. We were also introduced to new fellowships and grants from the ERS and the European Union. The JMC is currently discussing with ERS Research Director Maria Belvisi how to increase the number of fellowship applications from junior members. We are also investigating mechanisms to enable applicants to identify suitable host organisations to ensure career progression. An even bigger event was the Young Scientists' Networking Evening on Tuesday. As the name suggests, this is a magnificent opportunity for junior scientists to promote their networking and links internationally, identify future collaborators and exchange ideas with other juniors from all over the world, all while having a really good time. More than 300 young participants attended this year and definitely enjoyed the atmosphere. We believe these events are very important. Getting juniors together in a friendly environment enables everyone to meet colleagues from other countries and to exchange experiences and this is outstandingly beneficial in a large congress where new participants may feel a bit lost.

Just as important as social events like the Fellow's Get Together and the Networking Event is the scientific contribution of Junior Members. We would like to thank you for sending your abstracts, and to congratulate you for being accepted! This meeting had a high number of abstracts submitted by Juniors. Among the 4409 abstracts accepted for the Congress, 1796 were submitted by an author aged 35 years or under on the first day of the Congress. The total number of authors who were 35 years old or under is 1488 (as some have submitted more than one abstract), but still more are needed. To support you in that direction, we plan to come back to you in the forthcoming issues of Breathe with a featured series of short educational articles in practical academic and clinical skills that juniors usually need. Topics will include how to improve your poster, become a successful co-chair, peerreviewing, etc.

The importance of junior members cochairing sessions together with more seasoned scientists was highlighted in our previous News from the Underground. At this year's Annual Congress an average of $5 \%$ of chairs were junior members (fig. 1). 


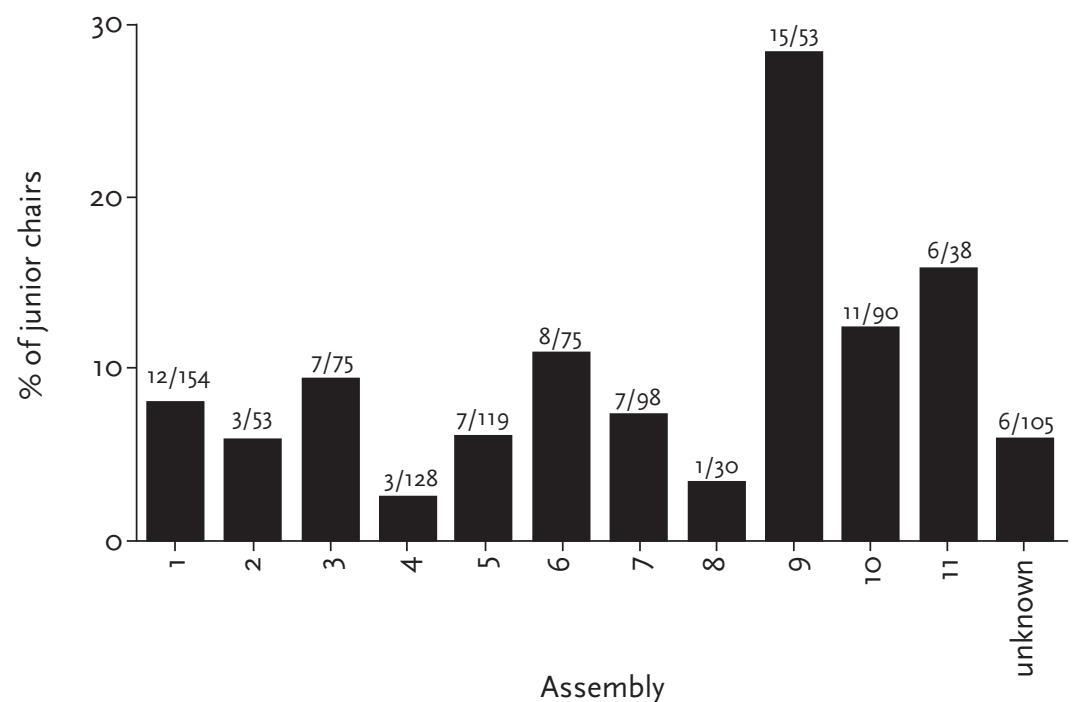

Figure 1

Proportion of junior members co-chairing sessions per Assembly.
It is the ambition of the JMC to increase this proportion in future meetings, and this has been discussed at the Assembly meetings. However, the simplest way is for you to contact your Assembly JMC representative. You can find all contact details of JMC representatives at juniors.ersnet.org/who-are-we.

Towards the same direction, junior members are particularly encouraged this year to send their scientific abstracts to the next ERS Lung Science Conference that will be held in Estoril March 2014. The deadline for submissions is $8^{\text {th }}$ November 2013. This year a large number of travel grants will be available for juniors who submit outstanding abstracts. This will be another great opportunity to communicate your ideas, promote your work and make your voice loud in the Society.

The ERS Junior Member Committee are: Anders Bjerg, Tiago Jacinto, James Chalmers, Georgia Hardavella, Alexandros Mathioudakis, Indre Butiene and Szymon Skoczynski. Please visit juniors.ersnet.org which we aspire to make a live forum for the exchange of experiences and net-working! 